\title{
La antropología de Boecio en el De Institutione Musica y el Contra Eutychen ${ }^{1}$
}

\author{
Manuel Antonio Correia Machuca²
}

Recibido: 31 de octubre de 2018 / Aceptado: 7 de abril de 2019

Resumen. El De Institutione Musica, uno de los primeros tratados científicos de Boecio, expone la relación entre el hombre y la música basada en la armonía musical del cuerpo y el alma, donde Platón y Aristóteles aparecen confirmando a Pitágoras, quien sería el creador de esta antropología. En nuestro análisis, la enseñanza de Boecio proviene del neo-pitagorismo de Nicómaco de Gerasa y es incompatible no sólo con las doctrinas correspondientes de Platón y Aristóteles, a quien Boecio dice honrar con la traducción de sus obras, sino con otros tratados, especialmente el Contra Eutychen que se analiza aquí, por tener un fuerte componente antropológico. La pregunta que nos hacemos es si Boecio era consciente de esta incoherencia doctrinal en su obra. Nuestra respuesta es positiva, es decir, que aunque las antropologías en rigor no son compatibles, la mente de Boecio no está en contradicción consigo misma, porque el Contra Eutychen y en general los tratados teológicos son respuestas originales del autor a problemas teológicos, mientras que el De Institutione musica y en general los tratados científicos no son originales ni pretenden serlo, sino que dependen de sus fuentes.

Palabras clave: aristotelismo; pitagorismo; platonismo; música; aritmética; Boecio; Nicómaco de Gerasa; teología.

\section{[en ] The anthropology of Boethius in the De Institutione Musica and Contra Eutychen}

Abstract. The De Institutione Musica, one of the first scientific treatises of Boethius, exposes the relationship between man and music based on the musical harmony of body and soul, where Plato and Aristotle appear to confirm and support Pythagoras, who would be the creator of this anthropology. In our analysis, the teaching of Boethius comes from the neoPythagorism of Nicomachus of Gerasa, and it is incompatible not only with the corresponding doctrines of Plato and Aristotle, whom Boethius says to be honoring with the translation of their works, but with other treatises, especially the Contra Eutychen, which is analyzed here, since it has a strong anthropological component. The question we ask is whether Boethius was aware of this doctrinal incoherence in his work. Our answer is positive, that is to say, that although the anthropologies are not compatible, Boethius' mind is not in contradiction with itself, because the Contra Eutychen and in general the theological treatises are the author's original answers to theological problems, while De Institutione musica and in general the scientific treatises are not original nor pretend to be, but depend on their sources.

Keywords: Aristotelianism; Pythagorism; Platonism; music; arithmetic; Boethius; Nicomachus of Gerasa; theology.

1 Este artículo ha sido posible gracias a Fondo nacional de desarrollo científico y tecnológico (Fondecyt, Chile) No 1170522. Una versión previa se presentó en el X Seminario de Estudios Patrísticos (1977-2017), Facultades de Teología y Filosofía, Pontificia Universidad Católica de Chile, Santiago de Chile, 2017.

2 Instituto de Filosofía, Pontificia Universidad Católica de Chile mcorreia@uc.cl 
Sumario: 1. Introducción; 2. Breve revisión del DIM I; 3. ¿Es compatible la antropología de DIM con Platón y Aristóteles?; 3.1. Platón; 3.2. Aristóteles; 4. ¿Es compatible la antropología pitagórica del DIM con la obra teológica de Boecio?; 5. Una reaproximación al modus operandi de Boecio; 6 . Referencias bibliográficas.

Cómo citar: Correia Machuca, M. A. (2020): "La antropología de Boecio en el De Institutione Musica y el Contra Eutychen”, en Revista de Filosofía 45 (1), 121-140.

\section{Introducción}

El De Institutione Musica (DIM) es un tratado científico elaborado por Boecio en cinco libros, al comienzo de su carrera intelectual, probablemente entre el 500 y el 510 de nuestra era. ${ }^{3}$ En él se propone entregar en latín una introducción (institutione) a la teoría de la música tal como fue desarrollada en la antigüedad tardía (I-II DC), principalmente por la escuela pitagórica. Se trata de un tema difundido en la cultura antigua. ${ }^{4}$ La empresa de Boecio consiste en hacer una sola exposición de los fundamentos y principios aritméticos de la música, evitando que otras fuentes y teorías contaminen esta fuente original pitagórica. Esto explica que la obra de Aristoxeno de Tarento no tenga lugar en el DIM y que se lo nombre solo para criticar su aproximación empírica a la teoría musical. ${ }^{5}$ En este sentido, el DIM tiene un modus operandi similar al de los tratados lógicos, donde la visión estoica sobre la lógica es criticada y alejada, prefiriéndose la visión peripatética de Alejandro de Afrodisias y, sobre todo, los reportes de Porfirio al comentario peripatético. ${ }^{6}$

La fuente más segura de los dos primeros libros del DIM son las enseñanzas del neopitagórico Nicómaco de Gerasa, ${ }^{7}$ razón por la cual es admisible su presencia intelectual en la introducción que Boecio hace a este tratado (DIM I, 1-2). Pero no todo en DIM proviene de él, pues, como ha sido destacado ya por A. Barbera, ${ }^{8}$ Boecio en DIM IV, 1-2, sigue con algunos $\operatorname{cambios}^{9}$ la Sectio Canonis, obra atribuida a Euclides el geómetra; y, en DIM V, y parte del IV, Boecio hace uso profuso de las Harmonicas de C. Ptolomeo. ${ }^{10}$ Ahora bien, como sabemos, además, que Porfirio comentó esta obra ptolemaica e incluyó otros muchos autores en su exposición sobre la música, ${ }^{11}$ entonces se hace plausible la hipótesis de que el material griego que Boecio dispone para DIM dependa de un tratado introductorio a la música del entorno escolar de Porfirio, y anterior a Proclo, tal como ocurre con las fuentes de sus obras lógicas.

3 Cf. N.H. Kaylor jr. and Ph. Edwards (2012), p. 252. También De Rijk, L.M. 1964. Y McKinlay 1907, pp. 123156.

4 Hay que notar que Marco Tulio Cicerón es nombrado por Boecio en DIM I, 1, 10, 185. También menciona las fuentes griegas de Arquitas, Aristoxeno, Ptolomeo y Albino. Además, algunos músicos griegos. Cf. DIM I, 1, 9-26, 185.

5 Cf. DIM II, 31, 20; III, 1, 21; III, 3, 18. En el index nominum de la edición de Friedlein para Teubner existe una lista completa de las apariciones de Aristoxeno en DIM.

6 Como es sabido, Boecio sigue a Porfirio en sus comentarios a la lógica de Aristóteles considerándolo una fuente muy confiable: doctissimus vir: cf. in Int. 2, 15, 276 (Meiser, C. 1877-1880. Ed.)

Cf. Bower (1978), p. 5.

Barbera (1991), pp. 1-3, y 48-49.

9 Cf. Barbera (1991), pp. 38-60.

10 Cf. DIM V, 4, 25; V, 5, 5; V, 8, 13; V, 11, 1; V, 14, 21, V, 18, 24 et al. Cf. Pedro Redondo Reyes (2002), p. cxv.

11 Cf. Barker (2015), p. cx. 
Si bien es comprensible que Boecio en los libros introductorios del DIM dependa de las enseñanzas de Nicómaco de Gerasa, no es fácil explicar por qué razón Boecio tenga que asumir sine critica una antropología pitagórica de amplio espectro, que no desarrolla posteriormente y que tampoco es coherente con la que él mismo asume en otras obras, especialmente en aquellas donde la crítica especializada asume correctamente que se trata de una obra original, que no tiene antecedentes en la historia respectiva de la disciplina, como ocurre con los tratados teológicos, en especial el quinto tratado, conocido como Contra Eytichen. De hecho, esta dependencia del DIM con su fuente reabre las dudas que Shiel (1990), seguido de otros autores, ha levantado en el siglo XX sobre el modus operandi del autor Boecio, y en especial sobre si es original su obra científica, y si lo es cómo y cuánto. ${ }^{12}$ En efecto, el caso particular del DIM propone no sólo la cuestión de cómo Boecio tomaba control de sus fuentes, que es la cuestión central tratada por los especialistas del siglo XX, sino que además abre una nueva cuestión relacionada con determinar si, y hasta qué punto, Boecio se preocupó de que las bases doctrinales de sus tratados fueran coherentes entre sí.

Las explicaciones actuales sobre el modus operandi de Boecio oscilan entre un autor que tiene el conocimiento científico suficiente para controlar y autorizar los contenidos de estos tratados y, en el otro extremo, un autor que se limita a traducir, sin ninguna originalidad ni en la forma ni en el contenido, las coacervatae sententiae (las opiniones acumuladas en los márgenes de los manuscritos griegos de los que hacía uso para sus traducciones y tratados), opinión esta última muy influyente, y que fue expresada de modo agudo por Shiel (1990), 361, y que por cierto empobrece la visión tradicional del autor Boecio (no de Boecio). ${ }^{13}$

El objetivo principal de este artículo es ofrecer una explicación sobre el porqué Boecio tendría a bien permitirse esta licencia, es decir, una antropología en el DIM que es incompatible o difícilmente ajustable con la que supone en otras obras, especialmente en su tratado teológico Contra Eytichen. La explicación que ofrecemos sostiene que el joven Boecio en DIM se limita a transmitir la doctrina que aparece en su fuente, mientras que el Contra Eutychen ofrece una respuesta original para un problema teológico inusitado en la tradición filosófica griega y que apremia a la autoridad eclesial de la época. Esta explicación nos conducirá finalmente a hacer hincapié en la diferencia que existe en su obra respecto de sus escritos científicos (donde se refiere a la disciplinas de las artes liberales) y sus tratados teológicos,

12 El problema de las fuentes de los escritos científicos de Boecio, especialmente de sus escritos lógicos, está lejos de resolverse, pero J. Shiel (1958), pp. 217-244 y (1990), pp. 349-372, hizo una contribución sustancial que puede aplicarse a todos sus escritos científicos: Boecio traduce las notas marginales del material griego que tiene a disposición para realizar un comentario o tratado. Su hipótesis ha producido una importante controversia también. Los autores involucrados en estudios específicos de algunos de los comentarios o monografías de Boecio no la han adoptado y, en algunos casos, han presentado artículos en su contra. Así, Stump (1974), pp. 77-93, Asztalos (1993), pp. 367-407. Un artículo que apunta específicamente a rechazar la hipótesis de Shiel es el de Ebbesen (1990), pp. 373-391. Chadwick (1981) y J. Barnes (1981), pp. 73-89 tampoco parecen dispuestos a aceptarla. Así también Magee (1989), p. 3, quien observa dificultades en la creencia de Shiel de que existieran códices griegos con anotaciones marginales antes de la enseñanza de Proclo en el IV-V DC. Pero, entre otros, De Rijk (1964), pp. 1-49 y pp. 122-162, Zimmermann (1991), Minio-Paluello (1957), pp. 358-365; y (1970), y en todas sus otras referencias a Boecio, han estado de acuerdo con Shiel. Una historia de este debate en el artículo de De Vogel (1971/2) pp. 49-66 y pp. 1-40. Sin embargo, este último artículo no se puede leer sin la corrección en el "Postcript" de 1972, p. 37.

13 A lo largo del artículo hacemos la distinción entre Boecio la persona y Boecio el autor. Su modus operandi, su originalidad, se refiere a su trabajo como autor, no a su persona. 
donde se manifiesta puramente su original comprensión de la filosofía griega a través de las fuentes que tenía a disposición.

Para proceder, el artículo se divide así: 1. Una breve revisión de la antropología del primer libro del DIM. 2. Discusión sobre si la antropología del DIM es compatible con las doctrinas de Platón y Aristóteles, a quien pretende honrar con la traducción de la totalidad de sus obras. 3. Discusión sobre si la antropología del DIM es compatible con otras obras de Boecio, en particular el tratado teológico ya nombrado, donde ofrece una muy importante solución al problema cristológico de la época. Y 4. Una reaproximación al modus operandi del autor Boecio.

\section{Breve revisión del DIM I}

La parte introductoria del tratado (I, 1-2), que es donde se expone la teoría en términos conceptuales, presenta centralmente a la figura de Pitágoras, a quien se le atribuye el origen de la teoría musical a través de una circunstancia providencial, según la cual habría descubierto las armonías aritméticas de la música luego de escuchar el sonido de unos martillos que golpeaban los yunques de una herrería (DIM, I, 10). ${ }^{14}$ Según comenta Boecio, Pitágoras con esto habría dado un ejemplo de cómo la razón humana es capaz de entender las reglas detrás de la música sensible y migrar hacia la consideración puramente matemática de la música (Pythagoras ad regularum momenta migraverit). ${ }^{15}$

Boecio distingue en el hombre la operación sensorial de la intelectual. Si bien esta distinción puede reconocerse como clásica en la filosofía griega, muy presente en autores como Platón y Aristóteles, Boecio no parece seguir a ninguno de estos autores cuando destaca el valor del sentido del oído, ya que reconoce no sólo que tiene la facultad de captar los sonidos y las diferencias auditivas, sino que el hombre a través de este sentido también se deleita o se turba dependiendo de la calidad de los sonidos escuchados. Si son dulces y ajustados al oído humano, habrá deleite; si, por el contrario, son dispersos y sin cohesión provendrá directamente una perturbación del ánimo y la mente.

Esta característica de la música es la razón por la cual Boecio sostiene que entre las ciencias matemáticas (la aritmética, la geometría, la música y la astronomía), llamada por él mathesis, se conforma una unidad imperfecta, porque si bien todas buscan teóricamente la verdad de su objeto, la música no sólo tiene que ver con el modo teórico de la verdad y su investigación, sino también con la moral y la política. Esto significa que la música tiene una propiedad que no está presente en las otras ciencias, a saber, poder teorizar sobre la verdad de las consonancias y sus relaciones aritméticas y, al mismo tiempo, influir en la práctica y la acción humana. En efecto, ni la astronomía, ni la aritmética, ni la geometría tienen este poder que la música tiene.

Esta doctrina es concordante con la que Boecio expone en el primer libro de su De Institutione Arithmetica (DIA) y donde es evidente su dependencia con la

\footnotetext{
14 Cum interea divino quodam nutu praeteriens fabrorum officinas pulsos malleos exaudit ex diversis sonis unam quodammodo concinentiam personare. (DIM I, 10, 3-6, 197.)

15 DIM I, 10, 19-20.
} 
Introducción a la Aritmética de Nicómaco. ${ }^{16}$ La doctrina en cuestión también sostiene que la enseñanza de las ciencias de la mathesis debe hacerse desde la ciencia más primitiva (la aritmética) hasta la más elevada (la astronomía). De hecho, lo que en el DIM es la mathesis, en el DIA (I, 1, 28,9) es el quadrivium/quadruvium, ${ }^{17}$ esto es, la doctrina que habla sobre la utilidad de las 4 artes reales (aritmética, geometría, música y astronomía) y su articulación interna a partir de la aritmética.

Boecio no se priva de ejemplos que hagan más clara la tesis que defiende y en general va a sostener que los pueblos gozan de aquella música que es semejante a sus costumbres. Los modos ásperos hacen feroces y salvajes a sus ciudadanos, mientras que los modos lascivos los hacen desvergonzados. Y es por esto que el mismo Pitágoras, según Boecio, conociendo el efecto que la música produce en los hombres, muchas veces les modificó su carácter e incluso sus mismas acciones solo por medio de la música. Reporta Boecio (DIM I, 1, 20-3, 184-185):

¿A quién en efecto le es desconocido que Pitágoras a un joven tauromenio, ebrio e incitado por los efectos de un son de modo frigio, lo volvió más apacible y dueño de sí mismo con un canto espondaico? ${ }^{18}$

Y agrega incluso que (DIM I, 1, 20, 185):

Ismenias de Tebas a muchos beocios, a quienes vejaban los tormentos del dolor de ciática, les curó y disipó todas las molestias a base de 'modos' $<$ musicales $>$. ${ }^{19}$

Es evidente que con la música estamos frente a uno de los enigmas más atractivos de la naturaleza y como Boecio dice (DIM I, 1, 26-6, 185-186):

A tal grado de notoriedad llegó la fuerza del arte de la música en los estudios de la antigua filosofía, que los pitagóricos cuando intentaban diluir en el sueño las preocupaciones diarias, se servían de ciertas cantilenas para que un dulce y tranquilo sopor se les fuera infiltrando. E igualmente para despertarse con otro tipo de modos purgaban el aturdimiento y la confusión del sueño. Ello sin duda conscientes de que toda la estructura de nuestro cuerpo y de nuestra alma está conjuntada a base de un ensamblaje musical. ${ }^{20}$

Boecio en este tratado juzga consecuentemente que la doctrina que sustenta la natural y espontánea acción de la música en los hombres es un asunto entitativo que comporta una determinada antropología. No se trata pues de asunto de origen social

16 Hoche (1866).

17 Cf. DIA I, 1, 28. El término latino consignado por Friedlein es quadruvium. Por tanto, éste es el origen del tradicional término quadrivium, usado en la lengua latina posterior. En DIA quadruvium aparece solo una vez.

18 Cui enim est illum ignotum, quod Pythagoras ebrium adulescentem Tauromenitanum subphrygii modi sono incitatum spondeo succinente reddiderit mitiorem et sui compotem?. Las traducciones al español desde el latín del DIM, a menos que se diga otra cosa, son reproducciones de las realizadas por Jesús Luque Moreno para la edición de Gredos (2009).

19 Ismenias vero Thebanus Boetiorum pluribus, quos ischiadici doloris tormenta vexabant, modis fertur cunctas absterisse molestias.

20 In tantum vero priscae philosophiae studiis vis musicae artis innotuit, ut Pythagorici, cum diurnas in somno resolverent curas, quibusdam cantilenis uterentur, ut eis lenis et quietus sopor irreperet. Itaque experrecti aliis quibusdam modis stuporis somni confusionemque purgabant id nimirum scientes quod tota nostrae animae corporisque compago musica coaptatione coiuncta sit. 
o cultural o de género, ya que sostiene prontamente que (DIM I, 1, 15-17, 186):

En efecto, eso lo experimenta también toda edad y todo sexo, sectores que, aunque separados por sus actividades, están, sin embargo, unidos por un único deleite de la música. $^{21}$

Todos estos ejemplos muestran, a juicio de DIM I, 1, 8-10, 187, que:

(...) es fácil entender y no dudar de que la música está por naturaleza conjuntada con nosotros de manera que aunque queramos no podríamos privarnos de ella. ${ }^{22}$

Y por esa razón agrega a continuación (DIM I, 1, 10-12, 187):

Por esta razón, hay que tensar la fuerza de la mente para que eso que por naturaleza es innato pueda también ser dominado una vez aprehendido por la ciencia. ${ }^{23}$

La doctrina antropológica que Boecio expone en DIM I, 1, halla aquí un pasaje muy significativo, ya que contrasta la mente humana con la naturaleza, sosteniendo que de lo que por naturaleza es inherente o innato (insitum), la mente humana puede tener un concepto a través de la ciencia (scientia possit comprehensum teneri). La ciencia, pues, no sin esfuerzo (intendenda vis mentis est), puede conocer la teoría y los fundamentos aritméticos de la música, de modo tal de promover una liberación intelectual de aquello que por naturaleza nos afecta. La doctrina queda caracterizada por su apego a la noción de armonía psicosomática y por su distancia a la idea clave de una separación total entre cuerpo y alma.

Por lo demás, en el segundo libro del tratado, Boecio (DIM I, 2, 20-23, 187) hace una distinción de tres tipos de música: la música mundana (mundana), la humana (humana) y la instrumental (constituta instrumentis) ${ }^{24}$ Boecio las distingue sobre la base de cuál es la más universal de todas. La mundana es la más universal, ya que corresponde a la armonía y orden regulado de los astros en el cielo: unos astros giran más bajo, otros más altos, pero todos forman un conjunto entre sí. Se trata pues del movimiento armónico de los astros, la conjunción articulada del universo. Es pues la música del mundo, donde nada es excesivo ni destruye al otro componente. Es pues también el origen de la teoría del movimiento armónico simple, un tema transversal a la física antigua, la clásica y la contemporánea.

Le sigue en universalidad la música humana, que es la que nosotros, como humanos, la experimentamos directamente en nuestro interior. Es el canto y sobre todo la cadencia de la poesía y las melodías que uno mismo crea. Es la responsable de nuestra propia armonía, en especial de la conjunción armoniosa entre la parte

21 Nimirum id etiam omnis aetas patitur omnisque sexus; quae licet suis actibus distributa sint, una tamen musicae delectatione coniuncta sunt.

22 Ut ex his omnibus perspicue nec dubitantes appareat ita nobis musicam naturaliter esse coniunctam ut ea ne si velimus quidem carere posuimus.

23 Quorcirca intendenda vis mentis est, ut quid, quod natura est insitum, scientia quoque possit comprehensum teneri.

24 Es cierto que no hay evidencia textual de que Nicómaco haya sostenido esta distinción; no se corresponde con otras triparticiones de la música del período clásico, como por ejemplo la que da Sexto Empírico en Adversus Mathematicos VI, 1 (Mau, J. 1954). Por lo mismo, es posible creer que Boecio sea el autor de ella, no obstante, la falta de información impide ratificarlo. 
sensible y la parte intelectual de nuestra naturaleza, de esa consonancia que se puede ejemplificar en la manera como las voces graves y las agudas se unen en consonancia musical. Aquí el motivo macrocosmos-microcosmos es patente y no cabe duda de que sigue siendo un motivo pitagórico el que influye en el reporte de Boecio.

La tercera es la música instrumental, generada ya por tensión de una cuerda o por el soplo de aire o por la percusión. En los capítulos siguientes (desde el 3 al 33) Boecio se ocupa de estos aspectos de la música, que por ahora nos saltamos, pero en el 34 retoma esta distinción para hacernos saber que solamente el hombre que se ocupa de la teoría aritmética de la música debe recibir en propiedad el título de músico. En efecto, basado en la distinción entre sentidos e inteligencia, Boecio va a sostener que sólo el que se ocupa de la música con la inteligencia, es decir, aquel que conoce intelectual y teóricamente la razón por la cual existe la armonía ya en el mundo ya en el hombre ya en los instrumentos, debe llamarse músico. Así, ni al cantar, ni al ejecutar un instrumento musical, ni siquiera al componer, somos músicos, sino al conocer la teoría aritmética y armónica que está detrás de la música sensible.

\section{3. ¿Es compatible la antropología de DIM con Platón y Aristóteles?}

A fin de realzar el fenómeno de la música como un hecho natural y universalmente valioso para todo hombre, Boecio en DIM I, 1-2, despunta dos ideas que son difíciles de reconciliar con nuestra actual comprensión de Platón y Aristóteles, a saber: a) una antropología, es decir, a una cierta noción de hombre, en que la afección musical es distinta de otra afección corporal por influir en el compuesto humano profundamente debido a razones cosmológicas. Y b) dar un lugar destacado a la música en la mathesis o quadrivium debido a su poder distintivo de afectar la actividad práctica humana, capacidad que no tienen las otras ciencias teóricas.

Lo que resulta más sorprendente es que este esfuerzo lo realice usando textos de la República y el Timeo de Platón. Incluso más sorprendente es una referencia a Aristóteles, en un breve pasaje, que parece expresar la intención de fundamentar sus opiniones y asertos. La cita no es totalmente convincente en sí misma, pero puede albergar el sentido que exponemos aquí. Dice Boecio (DIM I, 2, 189):

¿Qué otra cosa hay capaz de conjuntar entre ellas las partes de la propia alma, la cual, como place a Aristóteles, está conjuntada a base de lo racional y lo irracional?25

Aristóteles divide las partes del alma en racionales e irracionales en Ética a Nicómaco, I, 13 (1102a 28-30), pero no dice que estas partes están unidas por una armonía cosmológica como sugiere Boecio. Su uso parece incorrecto. La expresión Ut Aristoteli placet (como a Aristóteles le place $<$ hablar $>$ ) podría tomarse como que Nicómaco aquí critica a Aristóteles por no reconocer la armonía que pitagóricos y platónicos comparten, pero en DIA II, 42, 1-3, 139, Boecio cita nuevamente a Aristóteles junto a Platón y Pitágoras por coincidir en reconocer las tres medias

25 Quid est aliud quod ipsius interse partes animae coniungat, quae, ut Aristoteli placet, ex rationalibili inrationabilique coniuncta est? 
(medietates): la aritmética, la geométrica y la armónica. ${ }^{26} \mathrm{Y}$ en DIA II, 42, 6-21, 139, Boecio sugiere que la doctrina de las categorías de Aristóteles (que según, dice Boecio, son 10, en número pitagórico) era conocida por Arquitas y Platón.

La doctrina de DIM I, 1-2, si no se ve literalmente ni en Platón ni en Aristóteles, ha de ser una doctrina neopitagórica acogida en su tiempo por Nicómaco de Gerasa, que Boecio adopta sin que le resulte inconsistente con otras doctrinas o dudosa en sí misma. Entonces, cuando insiste en que ella recibe confirmación en Platón y en Aristóteles, Boecio estaría plegándose a una tesis de la escuela neopitagórica de Nicómaco. Es probable que la razón por la cual el joven Boecio incluye a Aristóteles en su esfuerzo por asentar esta antropología pitagórica, ${ }^{27}$ sea la creencia de que entre Pitágoras, Platón y Aristóteles no hay diferencias doctrinales importantes, sino más bien grandes convergencias. La doctrina es sorprendente y debe ser atribuida a la escuela de Nicómaco, ya que Boecio, en su comentario al De Interpretatione de Aristóteles, sólo sostiene que Platón y Aristóteles convergen en una misma verdad, afirmación que no incluye a Pitágoras y su escuela ${ }^{28} \mathrm{Es}$, pues, probable que durante el tiempo del surgimiento del neopitagorismo, lo que a veces se denomina el platonismo medio (s. I-II DC), tendencia de la cual Nicómaco es miembro activo, esta doctrina amalgamara estas tres filosofías que hoy consideramos tan distintas entre sí.

En primer lugar, señala Boecio (DIM I, 1, 4-5, 180) que Platón se expresó correctamente en Timeo 35b al decir que el alma del mundo está conjuntada según un convenio musical (mundi animam musica convenientia fuisse coniunctam), razón por la cual los hombres estamos conjuntados a imagen y semejanza con el universo (in nobis est iunctum convenienterque coaptatum). La semejanza es, pues, amiga y nos deleita, mientras que la desemejanza es odiosa y contraria. En seguida, Boecio confirma (DIM I, 1, 20-24, 180) la rectitud de sus principios interpretativos sobre la música al citar la República de Platón donde se dice que no hay ruina más grande para el Estado que desviarse de una música pudorosa y mesurada (Rep 424). Y por lo mismo, argumenta Boecio, siguiendo a su fuente, Platón allí prescribe una música adecuada para los niños, pero no cualquiera, sino la basada en modos vigorosos y simples, ya que Platón juzgaba que una música ajustada lo más posible a la moral es la gran salvaguarda del Estado.

Es sabido que R. Sorabji, no hace mucho tiempo atrás, en este mismo sentido, dijo que para nosotros los contemporáneos la idea de una concordia entre Platón y Aristóteles, era a perfectly crazy proposition ${ }^{29}$. Por esta razón, habría que preguntarse

26 Cf. DIA II, 52, 1-2, 167.

27 Las referencias a Platón en el DIA de Nicómaco son tan frecuentes como en DIM. Curiosamente, Nicómaco también en el DIA menciona al pasar a Aristóteles (cf. DIA II, 22, 1; y II, 28, 6).

28 Boecio dice casi al comienzo de su comentario al De Interpretatione de Aristóteles (in Int 2, 80, 1-6): "Y < al traducir las obras de Platón y Aristóteles $>$ no voy a desdeñar el reducir las opiniones de Aristóteles y Platón a una cierta armonía y mostrar cómo esas opiniones no son tan dispares acerca de todas las cosas, como muchos creen, sino que en la gran mayoría de los casos ellas están en un completo acuerdo.” (Meiser, C. 1877-1880. ed.). Boecio aquí, hace suyo lo que puede haber sido el objetivo del pensamiento y la actividad filosófica de Porfirio, quien había sostenido en su libro Que la escuela de Platón y la de Aristóteles es una y en otro, posiblemente el mismo, Sobre la diferencia entre Platón y Aristóteles, una radical unidad entre el pensamiento de estos dos autores. Lo que Boecio dice es plenamente coincidente: reducir a un acuerdo las opiniones de Platón y Aristóteles (in unam concordiam sententias Aristotelis Platonisque quodammodo revocare). Estos libros de Porfirio no sobrevivieron y los contenidos que llegaron posteriormente en árabe por el autor Al-miri no son representativos del total.

29 Sorabji aquí agrega que esta posición ha sido probadamente provechosa en términos filosóficos (philosophically fruitful): Sorabji 1990, p. 5. 
si también así deberíamos de tomar la opinión que defiende el joven Boecio, sobre la concordancia entre Pitágoras, Platón y Aristóteles. Tal como mostraré a continuación, es la noción de separación entre el mundo sensible y el inteligible, si bien sostenida de manera diferente por Platón y Aristóteles, la que no permite que prospere a) la propuesta neopitagórica de la musica coaptatione y b) la distinción especial de la música al interior de la mathesis $\mathrm{y}$, finalmente, la concordancia doctrinal entre Pitágoras, Platón y Aristóteles.

\subsection{Platón}

A primera vista, lo que Platón expone en República (376c, 398c, 399a, 410b y 522a), a saber, que la música es muy importante en la educación y no da lo mismo para la política y la sociedad el tipo de música que se enseñe y se practique, parece coherente con lo que Boecio expone. No obstante, hay que tomar en consideración que Platón en Fedón critica la tesis de origen pitagórico que el alma es una armonía y prefiere oponer el cuerpo al alma. ${ }^{30}$ Por esta razón, el alma no se desarmoniza al morir el hombre, sino que se separa del cuerpo donde residía. La misma separación del Bien respecto de las otras Ideas o formas, doctrina que Platón defiende en República, muestra que para Platón la idea de separación no es arbitraria ni ad hoc, sino que es clave en su antropología metafísica. Es por otro lado muy claro que ni Nicómaco ni el joven Boecio han aludido a la noción de separación para constituir su antropología, sino que, al contrario, para que tal antropología sea coherente con el fenómeno de la música, es necesario sostener que tanto en el cuerpo como en el alma hay una armonía de partes, así como que entre ambos, cuerpo y alma, existe una consonancia musical armonizada conforme a número.

En segundo lugar, Platón ciertamente sugiere el valor político de la música en República III, pero ni aquí ni en el resto del libro sugiere que la afección que el hombre padece por causa de la música tenga una raigambre cosmológica y menos que la música produzca un efecto directo, natural y espontáneo en el hombre por causa de la manera como éste está conformado antropológicamente. En general, la relación entre antropología y cosmología bien puede apreciarse estrecha, pero nunca al grado de creer que la sola música, sin el juicio y la deliberación del hombre, pueda -a través de proporciones y medias cosmológicas-determinar al ser humano. Tal vez esto es muy abstracto, pero ¿qué pensaría Platón o Aristóteles sobre la posibilidad de que la música sanara como Boecio dice que Pitágoras lo hizo con el joven tauromenio?

En tercer lugar, si bien Platón en Rep III y VII distingue la música instrumental o sensible de la música intelectual o armonía, en Rep VII Platón no dice como Nicómaco y el joven Boecio que las partes de la mathesis (esto es la geometría, la aritmética, la astronomía y la armonía) se identifican con la filosofía, ${ }^{31}$ sino que más bien son disciplinas preparatorias para el saber de la dialéctica y el buen gobierno de uno mismo y la ciudad. Más aún, en la alegoría de la línea de República VII Platón forma una línea ascendente, que va hacia las Ideas o Formas, especialmente la de Bien, mientras que los neopitagóricos parecen más bien formar un círculo cuyas

\footnotetext{
Las siguientes referencias a Platón, en: Cooper, J.M. (1997).

31 Cf. Nicómaco DIA I, 1, 1-2. (Sophia estin episteme tes en tois ousin aletheias). Y Boecio DIA 1, 1, 8-10. Est enim sapientia earum rerum, quae vere sunt, cognitio et integra comprehensio.
} 
partes se identifican con la mathesis o el saber de las cosas mismas. Además, aquí mismo Platón sostiene que la música inteligible o armonía es la puerta de entrada a la dialéctica, pero pone celo en distinguir que las Ideas están separadas de los números y las figuras geométricas y de toda cosmología y armonía, por inteligible que sean, pues la dialéctica es sin hipótesis -o sea totalmente abstracta-.

En cuarto lugar, en Timeo 69 c-d, Platón distingue el alma mortal del ser humano del alma inmortal, que identifica con el intelecto, y sostiene claramente que éste está separado del alma mortal y es en ésta, y no en el intelecto, donde existe un mikton, cuya base es aritmética y puede resolverse en número. ${ }^{32}$ Por tanto, nuevamente la noción de separación hace la diferencia entre Platón y los pitagóricos. En consecuencia, parece que el solo rendimiento de la noción de separación (horismos) en el ejercicio de distinguir la doctrina de Nicómaco y la de Platón, permitiría, a mi juicio, creer que Platón es partidario de la separación a secas entre lo inteligible y lo sensible, mientras que para los pitagóricos no hay tal separación sino que ambos estamentos están armónicamente juntos. ${ }^{33}$

\subsection{Aristóteles}

En los escritos de Aristóteles hay una consideración del fenómeno de la música. Especialmente en Política V, 4-5; VIII, 1340-41, ${ }^{34}$ el estagirita destaca que la música, como imitación directa de los estados morales del ser humano (ethos), tiene un poder moral y una utilidad política innegables. En general, su posición es conservadora respecto de la de Platón, pero con algunos cambios menores como por ejemplo cuando acepta en la ciudad que la música de la flauta -que Platón descarta como coadyuvante de la buena política- pueda ser de utilidad en ciertos casos. Sin embargo, en la filosofía de Aristóteles es aún más difícil encastrar la posición de Boecio en el DIM.

En primer lugar, Aristóteles en De anima I, 4 (407 b 25-408 a 18) ${ }^{35}$ rechaza la doctrina pitagórica de que el alma es una armonía numérica, porque armonía implica o bien la combinación de magnitudes o bien la proporción de los elementos en la mezcla, razón por la cual tiene más sentido sostener que la salud es una armonía que la propia alma humana lo sea.

En segundo lugar, DA I, 4408 b 20 y ss., separa claramente el intelecto humano de las otras facultades sensibles, e incluso de la misma alma mortal o sensitiva, sobre la base de que éste, el intelecto, es impasible. Incluso el mismo Aristóteles en DA III, 5 , en un muy discutido pasaje, hace la distinción entre dos tipos de intelecto uno el activo o formal y otro el pasivo y material, insinuando que el primero es el impasible y persistiría a la muerte.

32 Además, se lee en Timeo 34 b y ss., que el convenio del alma del mundo es aritmético, basado en intervalos armónicos, aritméticos y geométricos, pero no se ocupa la palabra 'música' ni un parónimo en esta descripción, ni se identifica la armonía a un modelo musical. Como sabemos, Nicómaco en su Introducción a la Aritmética I, 4, defiende la idea de que la aritmética es condición de la geometría, de la astronomía y de la música, pero no viceversa, razón por la cual es cuestionable que la consonancia entre el alma del mundo y el cuerpo del mundo sea en primer lugar de tipo musical, si primeramente no es -tal como exclusivamente explica Platón allí, aritmética.

33 Un pasaje que expresa muy claramente que los pitagóricos no separaron los números de los objetos sensibles se halla en la Metafísica de Aristóteles (I, 987b27-35).

34 Cf. también Aristóteles, Problemas 27 y 29 (Barnes, J. 1984. ed.).

35 De aquí en adelante abreviamos el tratado de Aristóteles De Anima como DA. 
La consonancia musical que une, según número, la sensibilidad y el intelecto, o la parte irracional con la racional, lo que Boecio traduce por musica coaptatione (DIM I, 1, 186), es precisamente lo que Aristóteles refuta al decir que el intelecto es separado. Por eso, es evidente que la alusión de Boecio a Aristóteles es muy superficial y completamente acrítica, incluso al punto de que se hace fuertemente incoherente con la cosmovisión de Boecio en el DIM. La justificación de por qué era importante recordar el nombre de Aristóteles en este párrafo atribuyéndole la doctrina de que la parte racional del alma humana y la irracional se conjuntan sólo busca aunar a Pitágoras, Platón y Aristóteles. Aristóteles en DA es muy cuidadoso al establecer una clara distinción entre sensibilidad e intelecto, a punto que los comentaristas aristotélicos entendían que la finalidad del DA no es probar que el alma humana es inmortal, sino que probar que sensibilidad se distingue formalmente del intelecto. ${ }^{36}$

En tercer lugar, la definición de sonido que Boecio acoge, a saber, percusión de aire, si bien es aceptada por Aristóteles, la idea de que los astros pudieren hacer música de acuerdo con su movimiento, esto es, la idea de una música mundana o universal, es rechazada por Aristóteles por falta de evidencia sensible. ${ }^{37}$ De existir la pretendida armonía cósmica de los pitagóricos debiese ser percibida por el oído humano, pero esto no ocurre, sino que más bien conocemos la armonía inteligible a partir de la existencia de una armonía acústica y sensible.

Nicómaco y Boecio tampoco notan que al acoger críticamente la teoría de la armonía de Aristoxeno, están criticando a Aristóteles o al menos su posición gnoseológica. Es sabido que aunque Aristoxeno aceptó ciertas tesis de los pitagóricos sobre la música, ${ }^{38}$ concebía ésta -tal como Aristóteles, de quien se dice fue su discípulo- como un efecto de la armonía acústica, planteando una teoría de la música y de la armonía en general de tipo empírica, precisamente por la influencia que Aristóteles ejerció sobre él en este punto. Por lo mismo, debió haber considerado que la aritmética no es la condición de la música, sino que la aritmética se aplica

36 Cf. en particular el comentado pasaje de DA I, 4, 408 b13-14: "El intelecto, empero, parece consistir en una cierta sustancia que permanece y que no se corrompe." (Mi traducción). Además, en esta misma línea de argumentación, se echa de menos el rol del hábito y las virtudes de la valentía y la temperancia, explicadas en Ética a Nicómaco (EN), como capaces de refrenar en nosotros la afección del dolor y del placer, lo cual levanta la cuestión de que muchas de las desarmonías sonoras pudieran no afectar o afectar mucho menos a aquel que tiene ya el hábito de escucharlas o aquel que simplemente ha desarrollado una capacidad positiva para no alterarse por su acción. Igualmente se echa de menos la noción de acto voluntario (bouletikós) y la elección (proairesis), tan centrales en EN.

37 Aristóteles De Caelo II, 9, 290b y ss. (Gredos trad.): "Resulta patente a partir de esto que la afirmación de que se produce una armonía de los cuerpos en traslación, al modo como los sonidos forman un acorde, ha sido formulada de forma elegante y llamativa por los que la sostienen, pero no por ello se corresponde con la realidad. A algunos, en efecto, les parece forzoso que, al trasladarse cuerpos de semejante tamaño, se produzca algún sonido, ya que también se produce con los próximos a nosotros, aun no teniendo el mismo tamaño ni desplazándose con una velocidad comparable: que, al desplazarse el sol y la luna, además de astros tan numerosos y grandes, en una traslación de semejante velocidad, es imposible que no se produzca un sonido de inconcebible magnitud. Suponiendo esto, así como que, en función de las distancias, las velocidades guardan entre sí las proporciones de los acordes musicales, dicen que el sonido de los astros al trasladarse en círculo se hace armónico. Y como parece absurdo que nosotros no oigamos ese sonido, dicen que la causa de ello es que, desde que nacemos, el sonido está ya presente, de modo que no es distinguible por contraste con un silencio opuesto: pues el discernimiento del sonido y el silencio es correlativo; de modo que, al igual que los broncistas no parecen distinguir los sonidos por su habituación al ruido, otro tanto les ocurre a los hombres".

38 En este punto y no en todos, ya que Aristoxeno adhirió a la tesis pitagórica de que la música tenía un efecto terapéutico en el ser humano. 
accidentalmente a la música sensible, porque si no hubiera acústica, no habría teoría, invirtiendo la relación que Boecio en DIM I propone entre música instrumental y la teoría de la música. Así, Boecio en DIM II, 31, 3-5, 267, dice:

Pero cuál es el juicio sobre estas cosas de Aristoxeno, quien otorgó todo el juicio a los oídos, lo relataré en otra parte. ${ }^{39}$

Y luego agrega (DIM III, 21-23, 268):

Pero puesto que Aristoxeno, el músico, confiaba todo al juicio de los oídos, estima $<$ erróneamente $>$ que estos semitonos no son como los <entienden $>$ los pitagóricos $(\ldots) .{ }^{40}$

En cuarto lugar, hay que considerar que Aristóteles también desafiaría la ordenación de la mathesis boeciana y, de ningún modo, aceptaría que la aritmética es anterior al resto de las otras ciencias del quadrivium, la geometría, la música y la astronomía. Nicómaco usa un argumento que, por cierto, está en Aristóteles. Dice Nicómaco, en DIA I, 4, que la especie no es posible sin el género, así como el médico se arruina si no está el hombre y éste si no está el animal, lo cual ciertamente hallamos en la Categorías de Aristóteles. Con todo, Aristóteles contradice a Nicómaco cuando en Física II, 2, sostiene con claridad que la aritmética y la geometría son posteriores a la experiencia, o sea, dependen, en el sentido que menciona Nicómaco, de los cuerpos físicos que existen y su sensación y memoria (asunto este último importante en la armónica de Aristoxeno). Más aún, cuando en Física II, 2, Aristóteles se pregunta en qué se diferencia el matemático del físico, sostiene que puede ocurrir que el físico y el geómetra tengan interés científico por un mismo objeto, por ej. la figura de la luna o el sol, pero si ocurre, ocurrirá de distinto modo, pues la geometría mira el círculo o la línea recta, pero no como física, sino como geométrica. Y la óptica, que es una ciencia sensible que Aristóteles puede bien comparar con la música sensible, mira la línea recta del geómetra, pero no como geométrica, sino como física. Lo mismo, pues, se debería decir, siguiendo a Aristóteles, de la aritmética y de la música: el músico mira la armonía aritmética, pero no como aritmética, sino como sensible. Y el matemático mira la armonía física (por ejemplo, el movimiento oscilante de una cuerda), pero no como física, sino como una realidad aritmética.

Por lo demás, esta relación epistemológica entre la razón y los sentidos corporales que Aristóteles expone aquí resulta difícil de compaginar con el hecho de que Boecio llame a la razón (ratio) 'señora' (domina) y a los sentidos 'esclavos' de ésta. También que moralice esta relación entre razón y sentidos y diga que la ratio es más honorable que la pericia artesanal, así como la señora lo es frente al sirviente. Más aún cuando agrega que la especulación racional y la teoría no necesitan de la actualización

39 Sed de his, quid Aristoxenus sentiat, qui auribus dedit omne iudicium, alias commemorabo.

40 Sed quoniam Aristoxenus musicus, iudicio aurium cuncta permittens, haec semitonia non arbitratur esse secundum Pythagoricos (...). Cf. también DIM V, 4, 19-24, 355. "Puesto que todos están de acuerdo en que el sonido es una percusión de aire, la diferencia ente la gravedad y la agudeza la establecían según teorías contrapuestas los que seguían a Aristoxeno y los pitagóricos. Aristoxeno ciertamente pensaba que las diferencias entre sonidos según la gravedad y la agudeza consistían en la cualidad. Los pitagóricos por su parte la ponían en la cantidad." (Quoniam vero sonum esse omnes consentiunt aeris percussionem. gravitatis atque acuminis differentiam diversa ratione ponebant Aristoxenum- secuti et Pythagorici. Aristoxenus quippe sonorum differentias secundum gravitatem atque acumen arbitrabatur in qualitate consistere, Pythagorici vero in quantitate ponebant). 
práctica para su ejercicio, aunque cuando los sentidos actúan sin razón actúan en vano. (DIM I, 34, 148).

\section{4. ¿Es compatible la antropología pitagórica del DIM con la obra teológica de Boecio?}

La pregunta que hacemos al autor Boecio es cuál es la razón para exponer una antropología pitagórica y luego ni seguirla ni usarla en aquellos momentos donde podría haberla usado; por ejemplo, en el quinto de sus Tratados Teológicos, que es más conocido como Contra Eutychen (CE). ${ }^{41}$ Aquí Boecio se desenvuelve con elementos tomados desde la lógica de Aristóteles, ${ }^{42}$ en especial desde la lógica condicional de los aristotélicos Teofrasto y Eudemo ${ }^{43}$ (que seguramente conocía desde su traducción de su tratado De hypotheticis syllogismis), para definir la noción de persona y entrar en el problema cristológico de la naturaleza de Cristo, dejando en evidencia que las bases antropológicas del DIM no son usadas ni en el análisis del problema ni en su resolución.

Además, las circunstancias en que se origina el CE son para Boecio tan importantes que resulta aún más extraño que no haya evocado los principios de las enseñanzas de Nicómaco. En efecto, el CE es una reacción personal al problema presentado a la asamblea del año 512, cuando los obispos del Este llegaron a Roma a solicitar al Papa Símaco $(† 514)$ una aclaración en el asunto cristológico y tomar posición en el debate. Esto lo sabemos con seguridad porque al comienzo del CE Boecio menciona un tiempo relativamente largo entre sus deseos de escribir el CE con motivo de esta asamblea y su realización concreta. No menos motivado debió haber estado Boecio a actuar en este sentido, sabiendo que el ascenso de un emperador católico en Bizancio (Zenón), y su gesto inmediato de derogar el Henótikon y promover una política pro católica, dejaba a la iglesia de Roma en una posición relevante para dar unidad teológica al credo. El interés de Boecio es, pues, terminar con el cisma acaciano cuyo fundamento son los extravíos de Nestorio (difisismo) y Eutiques (monofisismo), cuyas posiciones cristológicas justamente critica en $\mathrm{CE}$.

41 Contra Eutychen et Nestorium en: Boethius (1973).

42 Estos elementos no sólo son terminológicos (e.g., sustancia -corpórea, incorpórea, racional, irracional-, accidente, composición, etc.), sino también funciones analíticas tomadas desde la lógica aristotélica. Por el año del CE Boecio debe tener traducido, comentado y tratado el Órganon (aunque quizás su trabajo no contenga una traducción y un comentario a las Refutaciones sofisticas y los Analíticos Posteriores, si bien esto no prueba que no los conociera). Por lo mismo, Boecio está en condiciones de hacer uso de la lógica aristotélica como un instrumento. En el CE su uso se caracteriza por ser bastante completo y selectivo, ya que usa todos los recursos que son atingentes: la división y la definición, argumentos o silogismos hipotéticos, distinción de los significados ambiguos de los términos, y detección de las falacias involucradas. Esto explica que la discusión del CE sea tan precisa al detectar la falacia de cada posición herética y la suficiencia de la posición católica respecto de la naturaleza de Cristo y su persona.

43 En su De hypotheticis syllogismis I, 3, 21-30 (Obertello, L. ed. 1969), Boecio menciona a Teofrasto y Eudemo como la fuente de la teoría y dice: "Esto que he encontrado en unos pocos autores griegos de modo breve y confuso, y en ningún autor latino, lo dedico a tu consideración, después de haber sido completado por nuestro largo, aunque exitoso, esfuerzo. Cuando tú hubieres adquirido un conocimiento cabal de los silogismos categóricos, a menudo desearás información acerca de los silogismos hipotéticos, respecto de los cuales Aristóteles no escribió nada. Teofrasto, quien era un hombre capaz de desarrollar cualquier doctrina, solo expuso un resumen de estas cosas. Eudemo empero toca el punto desde una perspectiva más amplia, así como esparciendo las simientes, aunque no se ve sacar de ello ningún fruto.” Mi traducción. 
De este modo, es bastante notorio que en el CE Boecio no ocupa el esquema antropológico de Nicómaco en el DIM, pero además es manifiesto que tampoco podría haberlo ocupado, por lo cual no queda sino aceptar que Boecio ha relegado esas explicaciones sobre el ser humano en este tratado teológico, dando pie para creer que, mientras escribía sus tratados científicos no se preocupó de la consistencia de las bases teóricas de sus fuentes. En efecto, para Boecio una cristología coherente requiere que se distingan precisa y formalmente las posibilidades lógicas que existen para unir a la persona con la naturaleza en general. Tal distinción se halla explícita al final de la discusión, donde dice:

Por lo que, si pueden ser cuatro < posibilidades>, ni una más ni una menos, a saber, que en Cristo hay o bien (i) dos naturalezas y dos personas, como dice Nestorio, o bien (ii) una persona y una naturaleza, como dice Eutiques, o bien (iii) dos naturalezas pero una persona, como cree la fe católica, o bien (iv) una naturaleza y dos personas, entonces -puesto que hemos ya refutado en esa argumentación en contra de Nestorio que pueda haber dos naturalezas y dos personas, y puesto que ya mostramos que lo que propone Eutiques no puede ser, a saber, que hay una persona y una naturaleza, y puesto que hasta aquí no ha existido alguien tan tonto como para creer que en Él pueda haber una naturaleza y dos personas-, queda que sea verdadera esta $<$ posición $>$ que pronuncia la fe católica, a saber, que hay doble naturaleza pero una persona (CE VII, 80). ${ }^{44}$

De este modo, si la posición de Nestorio es inaceptable, una de las otras tres es verdadera. Pero dado que la posición de una natura-duae personae es indefendible (y en verdad nadie existe que la haya defendido), lo que queda responder es si la posición de Eutiques (que critica la solución de Nestorio) o la posición de la fe católica es la cierta. Boecio tiene descritas estas posiciones heréticas diciendo que:

Nestorio correctamente creyó que la naturaleza de Cristo era doble pero sacrílegamente creyó que las personas eran también dobles, mientras que Eutiques correctamente creyó que la persona de Cristo era una, pero sacrílegamente creyó que la naturaleza de él era también única (CE V, 15-20). ${ }^{45}$

Las posiciones de Nestorio y Eutiques tienen algo en común que no está en la posición católica, a saber, que evitan que en Cristo haya dos naturalezas, la divina y la humana. Nestorio prefiere creer que las dos naturalezas obligan a que haya también dos personas, y Eutiques prefiere creer que hay solo una naturaleza (la divina) y una persona. De este modo, ninguno arriesga entrar en una explicación en la que lo divino y lo humano se unan. Porque quien acepta dos naturalezas (Nestorio) también duplica las personas -que, por lo demás, tampoco se ven en las Escrituras. Y quien no duplica las naturalezas (Eutiques) no tiene necesidad de explicar cómo

44 Mi traducción: Quocirca, si quattuor haec neque ultra neque infra esse possunt ut in Christo aut duae naturae sint duaeque personae ut Nestorius ait, aut una persona unaque natura ut Eutyches ait, aut duae naturae sed una persona ut catholica fides credit, aut una natura duaeque personae, cumque duas quidem naturas duasque personas in ea quae contra Nestorium dicta est responsione convincerimus (unam vero personam unamque naturam ese non posse Eutyche proponente monstravimus neque tamen tam amens quisquam huc usque exstitit, ut unam in eo naturam crederet sed geminas personas), restat ut ea sit vera quam fide catholica pronuntiat geminam substantia, sed unam ese personam.

45 Mi traducción: Itaque Nestorius recte tenens duplicem in Christo esse naturam sacrilege confitetur duas esse personas; Eutyches vero recte credens unam esse personam impie credit unam quoque esse naturam. 
ellas están unidas. De este modo, la posición católica tiene un desafío racional único, que es mostrar cómo puede ocurrir que en Cristo haya dos naturalezas, la humana y la divina, y una persona, la persona de Cristo. Y es aquí, en este desafío que se presenta a la razón humana, donde Boecio precisamente podría haber confiado en la antropología pitagórica del DIM para enfrentar la exigencia que levanta la posición católica y de la que depende la unidad de la cristiandad.

Pero no solo no se halla en CE nada relativo a aquella antropología pitagórica que con tanta elocuencia describe el joven Boecio en DIM, sino que además hay una implícita refutación de la clave pitagórica. En efecto, Boecio distingue las siguientes posibilidades de unión de las dos naturalezas (la humana y la divina), a saber:

a) ambas sustancias se disuelven in infinitum

b) la sustancia divina se absorbe en la humana

c) la humana se absorbe en la divina

d) cada una permanece en sí misma

Es claro que ninguna de ellas, salvo la d), la unión hipostática, es conforme a lógica, pues las posibilidades a), b) y c) tienen un grave defecto común, a saber, suponen que la naturaleza divina puede cambiar y dejar de ser lo que es, lo cual es inaceptable para la razón o la lógica (iure dicit). Además, las tres suponen que las naturalezas divina y humana tienen algo en común para transformarse entre sí, pero aquello es imposible, pues una es inmutable y simple, mientras que la otra es mutable y corporal. Y ocurre así también que tampoco entre el pasto y el bronce hay un elemento material común para que uno se transforme en el otro. Según la lógica, no puede ser más que la unión hipostática la alternativa correcta. Cristo es, pues, una persona y dos naturalezas, la divina y la humana, perfectas, que se unen sin que se confundan. Cristo es así consustancial con el hombre por su naturaleza humana, y consustancial con Dios por su naturaleza divina. Por eso Boecio considera importante hacia el final de la discusión que se aclare el sentido de la expresión 'consistir de dos naturalezas' (VII, 4-31), pues hay dos significados para esta frase: o bien significa que algo es de dos naturalezas, como el agua y la miel, en cuya combinación se mezclan ambas (y esta es la manera, según Boecio, en que Eutiques entendió la doble naturaleza de Cristo que se hizo una después de la encarnación), no permaneciendo ninguna en su propia naturaleza, o bien una cosa puede consistir de dos naturalezas en el sentido de que ambas permanecen, como en el caso que decimos que una corona es hecha de oro y gemas, ya que aquí ni el oro se convierte en gemas ni viceversa, sino que permanecen cada una de las naturalezas en sí mismas.

Si Boecio creyera en la antropología del DIM, hubiere aceptado como plausible la posibilidad en a), apoyándola con la idea de la armonía matemática. Pero es claro que la materia en cuestión exige separar completa o formalmente una naturaleza de la otra, razón por la cual tampoco las posibilidades descritas en b) y c) son aceptables.

Más aún, es notorio que, si Boecio hubiese adoptado la antropología pitagórica del DIM para resolver esta cuestión cristológica, no hubiese encontrado la fórmula resolutoria que establece que Cristo es una persona y dos naturalezas. En efecto, si la antropología el DIM se utilizara para resolver o siquiera analizar este problema, tendríamos que inferir que en Cristo se halla un alma y un cuerpo armónicamente compuestos, esto es, según una armonía musical (musica coaptatione), tal como se da en cada ser humano. Pero, además, la naturaleza divina de Cristo debería hallarse 
armónicamente compuesta con su naturaleza humana, ya de modo natural ya de modo metafísico, lo cual implicaría que una parte de esta naturaleza humana se relaciona con una parte de la naturaleza divina a través de una fórmula aritmética que armoniza y hace posible la unión de estas dos naturalezas diferentes entre sí.

El pitagorismo de Nicómaco no puede evitar que estas naturalezas tan diferentes entren en relación. No obstante, Boecio en su discusión rechaza tajantemente que la divinidad de Cristo se halle mezclada con la naturaleza humana, porque a su juicio, la razón indica que en Cristo las dos naturalezas, la humana y la divina, subsisten cada una en y según su propia naturaleza, y por tanto ni la naturaleza divina se absorbe en la humana, ni al revés, ni tampoco hay una mezcla infinita entre ambas naturalezas distintas. La fórmula boeciana en el Contra Eutychen, a saber, la unio inconfusa, así como la distinción entre 'consistir de dos naturalezas' y 'consistir en dos naturalezas', están suponiendo la noción de separación más que la noción de unión armónica. De hecho, la unión de dos naturalezas diferentes, aunque sea armónica, impediría salvar la pureza de la divinidad de Cristo, y finalmente impediría la fórmula una persona y dos naturalezas, para quedar en una naturaleza armónicamente compuesta y una persona.

Según Boecio en el Contra Eutychen, la lógica se identifica con la razón y demuestra, al contrario, que deben subsistir ambas naturalezas, separadas una de otra, y unificarse solo en la persona de Cristo, manteniendo la subsistencia de ambas sin confusión. La persona de Cristo es así, humana y divina, sin que se confundan sus naturalezas ni que entren en una suerte de relación aritmético-musical en la que obligadamente las partes de una se relacionan con las partes de la otra según una proporción aritmética. ${ }^{46}$

\section{Una reaproximación al modus operandi de Boecio}

La pregunta que espera respuesta es por qué Boecio explica la teoría de la música a través de un expediente que luego, en la medida que se desarrolla su ocupación intelectual, no vuelve a usar ni relacionar con las nuevas temáticas que sus escritos reclaman.

En este artículo, para tratar la cuestión de la originalidad de los tratados científicos de Boecio, se ha hecho un planteamiento que ha desembocado finalmente en la cuestión de si él era consciente o no de estas inconsistencias en sus fuentes. La propuesta de Shiel 1990, 361, se puede traducir a estos términos y decir que (i) Boecio es inconsciente, porque su modus operandi se reduce sólo a traducir las explicaciones que encuentra en su material griego. ${ }^{47}$ Esta posición excluye otras dos

46 En general, el CE es un tratado teológico con un fuerte ascendente aristotélico en su método y en sus términos. De hecho, es notoria la presencia de la lógica hipotética de los aristotélicos junto con las nociones de naturaleza y sustancia (aun cuando Boecio critique a Aristóteles -injustamente por lo demás- por creer que las sustancias son solo materiales). No obstante, entre los estudiosos de este tratado hay acuerdo de que se trata de una especulación original que no tiene precedente en la historia de la filosofía ni la teología católica. Por lo mismo, el que recurra a la noción de sustancia subsistente y a través de ella a la noción de separación, sugiere fuertemente que Boecio ha olvidado lo que pudiere aportar en esta discusión teológica una antropología pitagórica como la expuesta en DIM. Igualmente ha dejado completamente fuera la doctrina de que entre Pitágoras, Platón y Aristóteles existe una convergencia hacia una única verdad.

47 Shiel (1991), p. 361, caracteriza el modus operandi de Boecio con una frase del comentario al De Interpretatione (in Int. 2, 2-6, 421, Meiser ed.): nam et plurimorum sunt in unum coacervatae sententiae et duorum ferme 
explicaciones: que (ii) Boecio es consciente, pero creía y mantuvo la creencia de la armonía profunda entre Pitágoras, Platón y Aristóteles hasta sus últimas obras; y que (iii) Boecio durante su juventud aceptó las doctrinas neopitagóricas, pero luego, al conocer y hacerse familiar con las obras lógicas de Aristóteles y sus comentaristas, conscientemente transformó su posición original en una filosofía más definida por el aristotelismo.

En DIM, como en el resto de sus obras científicas, Boecio es dependiente tanto de la autoridad de su fuente como de sus contenidos. De hecho, siempre está reconociendo su fuente cuando es conocida e indicando claramente que los contenidos del tratado han sido tomados desde otros autores. Una buena caracterización de esta actitud se aprecia en uno de sus tratados lógicos, el De syllogismo categorico, donde (101, $6=$ 829 D5) precisa su modus operandi: $:^{48}$

Y obtuve estas cosas desde una Introducción a los Silogismos Categóricos, siguiendo a Aristóteles mayormente, y tomando prestado algunas cosas de Teofrasto y Porfirio, cuanto la brevedad de una introducción me lo permitía. ${ }^{49}$

No hay razón para creer que la táctica de DIM y DIA sea otra que la que aplica en sus obras lógicas. El rol que juega Porfirio en éstas, explicando las doctrinas lógicas de Aristóteles y criticando las posiciones contrarias, lo hace Nicómaco en aritmética y música, explicando las doctrinas de Pitágoras y sus continuadores, distinguiéndolas de las posiciones contrarias de Aristoxeno y sus seguidores.

Por tanto, el arte de Boecio en sus tratados científicos se encuentra más bien en elegir la escuela adecuada para la materia a tratar, seleccionar sus fuentes en la medida de lo posible, ${ }^{50} \mathrm{y}$ alejarse de las doctrinas que no están en esa línea argumental. Esto es más que lo que Shiel 1990, 361, considera insuficientemente original, ${ }^{51}$ ya que el caso de los tratados no es el mismo que el de los comentarios, porque éstos siguen el texto de Aristóteles en orden, pero los tratados no siguen un solo texto y van más allá de los límites teóricos impuestos por el autor correspondiente. ${ }^{52}$

Esta convicción debería desechar la primera hipótesis basada en los resultados de Shiel 1990, ya que en DIM, como en sus tratados lógicos, Boecio dispone de un material griego para su obra, pero no hay una presentación o exposición hasta que él, como autor, se la da. Hay desde luego ciertos patrones de orden formal que se conocen en la educación de la lógica en su época o que se han transmitido entre

annorum spatium continuo commentandi sudore consumpsimus. En su traducción se lee: "For there are scholia of numerous points heaped up all together and so I have spent almost two years in a constant sweat of writing comments". Entonces Shiel concluye "The translation of these various marginalia and the arrangement of them into a continuous commentary according to the order of Aristotle's words would seem to be Boethius' only title to originality".

48 La edición de Boecio en: Thomsen Thörnqvist (2008).

49 Mi traducción. Cf. Thomsen Thörnqvist (2008), p. 157, 6 y ss.

50 Esta selección de autores y obras del mundo antiguo, tanto cuanto su educación y ambiente pudieron ofrecerle, no es muy amplia, sino que Boecio más bien echa de menos otras fuentes griegas como la obra de Temistio; incluso de algunas en latín como la de Albino, del cual Boecio dice conocer sus escritos geométricos, pero no los de lógica. (in Int 2, 4, 4-6, Meiser ed.)

51 Shiel (1991), p. 361. "the arrangement of them $<$ sc. las notas marginales que Boecio traduce $>$ into a continuous commentary according to the order of Aristotle's (...)".

52 La indicación en DIM de Ptolomeo, Albino, Arquitas, y otros autores, sugiere que Boecio va más allá de Nicómaco. Y en sus tratados lógicos, la mención de Teofrasto, Eudemo, Porfirio y Cicerón, indica que Aristóteles no es el único autor consultado. 
los tratadistas, ${ }^{53}$ pero la obra no está realizada sin una presentación teórica que dé cuenta de la materia en cuestión en su totalidad. Realizar tal presentación es más que traducir de manera mecánica las glosas de su códice siguiendo el texto del autor comentado. La consideración más realista, pues, apunta hacia la segunda y tercera hipótesis.

Pero la segunda hipótesis, a saber, que Boecio creía seriamente que Pitágoras es una figura esencial para explicar la presunta armonía profunda entre las enseñanzas filosóficas de Platón y Aristóteles, ya la hemos dado por improbable, puesto que Boecio no menciona esta armonía en ninguna otra obra, ni menos en sus escritos sobre teología, donde las doctrinas supuestas son otras distintas y, por cierto, incompatibles con sus primeras concepciones pitagóricas. De hecho, como vimos, no recurre ni a la terminología pitagórica ni a la doctrina antropológica de esta escuela para explicar asuntos teóricos propios de la teología cristológica, sino más bien a una doctrina teológica más coherente con el aristotelismo, en el que la unión de dos naturalezas diferentes en Cristo, la divina y la humana, se unen sin confusión, manteniendo la separación de las naturalezas respectivas.

Estos resultados hacen creer que la más probable de las tres alternativas revisadas sea la tercera, la que alude a una evolución en su pensamiento. El caso es, entonces, que Boecio durante el desarrollo de sus escritos científicos ha ido no solo comprendiendo en una exposición, a menudo precisa y clara, las doctrinas traducidas y tratadas, sino que también se ha ido identificando con su verdad. Esto explicaría por qué el DIM y el DIA, que son obras de juventud, adoptan una antropología de tipo pitagórica, para exponer sobre música y aritmética, que no va a permanecer en sus obras posteriores dedicadas a la lógica de Aristóteles, ni menos en los tratados teológicos donde la jerarquía de los problemas requiere de categorías conceptuales diferentes y de una total originalidad para su resolución.

De modo que, entonces, si estamos en lo correcto, se puede hacer una distinción en las etapas de producción de sus escritos científicos, que es la siguiente:

(i) Cuando el joven Boecio redacta sus introducciones a la aritmética y a la música, adopta una antropología de tipo pitagórica, tal cual se halla en Nicómaco de Gerasa.

(ii) Luego, y mientras traduce, comenta y escribe tratados sobre la lógica de Aristóteles, Boecio se distancia de esta antropología, no solo porque en general los pitagóricos no aportan a las discusiones de la lógica, sino porque se hace familiar con las doctrinas peripatéticas y sus supuestos antropológicos.

(iii) Finalmente, al abordar algunos problemas cristológicos, desarrolla originalmente una terminología asentada en el aristotelismo y un método de razonamiento lógico, muy similar al que conoció, junto a los peripatéticos Teofrasto y Eudemo, en su tratado sobre los silogismos hipotéticos (De hypotheticis syllogismis), y da muestras de concordar con una antropología aristotélica, esto es, hilemórfica.

Esta transformación intelectual del joven Boecio parece ser más importante que la dependencia textual que puede o no haber tenido en la elaboración de sus tratados y comentarios, y desde ya nos muestra que una gran obra no depende solo de la originalidad con la que se adoptan las doctrinas de otros (originalidad textual), sino de la originalidad de su proyecto.

En este sentido, una de las certezas que tenemos sobre el modus operandi del autor Boecio es esta evolución de su pensamiento a partir de sus escritos científicos y

53 Cf. Correia (2017), pp. 1035-1052. 
que culmina en una obra original en la que resuelve problemas teológicos inusitados, que la tradición filosófica griega no había tratado - ni tenía cómo hacerlo-.

\section{Referencias bibliográficas}

Asztalos 1993. "Boethius as a Transmitter of Greek Logic to the Latin West: The Categories", in Harvard Studies in Classical Philology, vol. 95, 367-407.

Barbera, A. 1991. The Euclidean division of the Canon. Greek and Latin sources. Lincoln: The University of Nebraska Press.

Barker, A. 2015. Porphyry's Commentary on Ptolomy's Harmonics: A Greek text and annotated translation. Cambridge, 2015: Cambridge University Press.

Barnes, J. 1981. "Boethius and the Study of Logic", Boethius His Life, Thought and Influence, M. Gibson (Ed.), Oxford 1981, 73-89.

Barnes, J. 1984. Ed. The Complete Works of Aristotle. The Revised Oxford Translation. J. Barnes (ed.). Two Vols. Princeton, New Jersey: Princeton University Press).

Boecio. Contra Eutychen et Nestorium, en: Boethius. The Theological Tractates. Transl. H.F. Stewart, E.K. Rand and S.J. Tester. Cambridge Massachusets 1973: Harvard University Press.

Bower, C. 1978. "Boethius and Nicomachus: An essay concerning the sources of De Institutione Musica", Vivarium, 6, 1, 1-45, p. 5.

Chadwick, H. 1981. Boethius. The Consolation of Music, Logic, Theology and Philosophy. Oxford: Oxford University Press.

Cooper, J.M. 1997. ed. Plato. Complete Works. Indianapolis/Cambridge: Hackett Publishing.

Correia, M. 2017. "Logic in Apuleius and Boethius", Revista Portuguesa de Filosofia, 73, 3-4, 1035-1052.

De Rijk 1964 “'On the Chronology of Boethius' works on Logic (I and II)”, Vivarium, vol. 2, parts $1 \& 2,1-49$ and 122-162.

De Vogel, C. 1971/2. "Boethiana (I and II)", Vivarium vols. 9 - 10, 49-66 y 1-40.

Ebbesen, S. 1990. "Boethius as an Aristotelian Commentator", en Aristotle Transformed, R. Sorabji (ed.), London, 373-391.

Friedlein, G. 1867. ed. Anicii Manlii Torquati Severini Boetii De Institutione Arithmetica libri duo. De Institutione Musica libri quinque. Accedit Geometria quae fertur Boetii. Leipzig: Teubner.

Hoche, R. 1866. ed. Nicomachi Geraseni Pythagorei. Introductionis Arithmeticae libri II. Leipzig: Teubner.

Kaylor jr, N.H. and Ph. Edwards. 2012. (eds.). A Companion to Boethius in the Middle Ages. Leiden, Boston: Brill.

Luque, J. et al. 2009. Boecio. Sobre el fundamento de la música. Cinco libros. Introd., trad., y notas Madrid: Gredos.

McKinlay, A.P. 1907. "Stylistic tests and the chronology of the works of Boethius, in Harvard Studies in Classical Philology, XVIII: 123-156.

Magee, J. 1989. Boethius on Signification and Mind, Leiden: Brill.

Mau, J. 1954. ed. Sexti Empirici Opera. Vol. III. Adversus Mathematicos. Leipzig: Teubner.

Meiser, C. 1877-1880. ed. Anicii Manlii Severini Boetii Commentarii in Librum Aristotelis PERI ERMHNEIAS. Prima et secunda editio, Leipzig: Teubner.

Minio-Paluello, L. 1957. "Les traductions et les commentaires aristotéliciennes de Boèce, in Studia Patristica II", Texte und Untersuchungen zur Geschichte der altchristlichen Literatur 64, pp. 358-365, p. 360. 
Minio-Paluello, L. 1970. "Severino Boezio", en Enciclopedia Italiana, Roma.

Obertello, L. 1969. ed. Boecio. De Hypotheticis Syllogismis, Brescia: Paideia Editrice.

Pedro Redondo Reyes. 2002. La Harmónica de Claudio Ptolomeo. Edición crítica, introducción traducción y comentario. Tesis doctoral, Murcia, 2002, España.

Shiel, J. 1990. "Boethius' Commentaries on Aristotle", en: Aristotle Transformed, R. Sorabji (ed.) London, 349-372; texto original en Medieval and Renaissance Studies 4, 1958, 217 44).

Sorabji, R. 1990 "The Ancient Commentators and Their Influence", Aristotle Transformed. The ancient commentators and their influence. R. Sorabji (ed.), 1-30. London: Duckworth. Stump, E. 1974. "Boethius's Works on the Topics", Vivarium 12, 2, 77-93.

Thomsen Thörnqvist, C. 2008. ed. Anicii Manlii Seuerini Boethii De syllogismo categorico. A critical edition with introduction, translation, notes and indexes. Studia Graeca et Latina Gothoburgensia LXVIII, University of Gothenburg: Acta Universitatis Gothoburgensis.

Zimmermann, F.W. 1991. Al-Farabi's Commentary and Short Treatise on Aristotle's de Interpretatione. Transl., introd. and notes, Oxford: Oxford University Press. 